\begin{tabular}{|l|l|}
\hline Journal Code: APHR & Proofreader: Elsie \\
\hline Article No: APHR12034 & Delivery date: 20 Feb 2014 \\
\hline Page Extent: 18 & \\
\hline
\end{tabular}

\title{
Identifying leadership potential in an Australian context
}

\author{
Ashlea C Troth Griffith University, Australia \\ Christopher Gyetvey Australian Taxation Office, Australia
}

\begin{abstract}
There is increasing recognition that identifying leadership potential is vital for long-term organizational survival. Using a sample of 166 Australian public service employees, and their 149 managers, this article empirically examines the role of general mental ability, problem-solving skill, emotional intelligence, employee engagement and career aspiration in identifying leadership potential. Both manager and employee self-ratings of leadership potential perceptions are considered as well as the presence of rater effects. Manager perceptions about problem-solving ability, engagement and aspiration predicted their ratings of employee future leadership potential. Employee self-ratings, apart from aspiration, did not. Rater effects were found. We discuss the implications of these results and suggest some strategies to more closely align managerial and employee views of leadership potential.
\end{abstract}

Keywords: Australian public service, leadership potential, performance assessment

\footnotetext{
Key points

1 Australian organizations recognize the need to better retain and develop its talent.

2 Identification of the factors that predict leadership potential ratings of employees is vital.

3 Problem-solving ability, engagement and aspiration are important when assessing leadership potential.

4 It is important for managers and employees to openly discuss what skills, abilities, attitudes and behaviours managers consider important for future leadership development.
}

Australian and New Zealand organizations traditionally prioritize their human resource investment towards the recruitment and selection of talent rather than the development and retention of talent (Freyens 2010; Holland, Sheehan and De Cieri 2007). A 2005 survey of over 1300 Australian human resource managers revealed only 39 percent of respondents reported career management as a priority area and only 37 percent reported initiatives associated with skill development as significant areas for policy development

Correspondence: Associate Professor Ashlea C Troth, Griffith Business School, Griffith University, Brisbane, Qld 4111, Australia; e-mail: A.Troth@griffith.edu.au

Accepted for publication 17 January 2014. 
(Holland, Sheehan and De Cieri 2007). From a resource-based view, it seems many Australian and New Zealand organizations are yet to fully support an integrated approach for their future leaders that advocates long-term investment in core competencies (Barney and Wright 1998). This is despite their increasingly knowledge-based economies that promote leadership identification and development as the key to long-term organizational renewal (Hutchings and Holland 2007).

The Australian Public Service (APS) has recently recognized the need to retain and develop its talent to meet the challenges of a modern public service. In 2010 the Moran Review released a reform agenda to ensure a high performing APS for the future (Advisory Group for the Reform of Australian Government Administration 2010). One of the four broad areas identified to strengthen performance included the provision of a strong leadership and strategic direction. To support this objective a specific recommendation was made to improve talent management across the APS. The APS Commissioner similarly called for a robust succession strategy that concentrated on the internal identification and development of talented employees, especially given an aging workforce and key leadership roles skewed towards older workers (APSC 2010; Freyens 2010). The main aim of this study is to identify some of the factors that predict leadership potential ratings of employees within the APS context. Our focus is on a specific department recognized as leading the way in organizational development and human resource practices within the APS and which is currently facing the aforementioned challenges.

There is a small but growing body of empirical work in the area of identifying leadership potential (e.g. Bhatnagar 2007; Dries and Pepermans 2007, 2008, 2012; Hirschfield and Thomas 2011; Marshall-Mines et al. 2000; Vloeberghs, Pepermans and Thielemans 2005) that has been conducted primarily in the profit or defense sector. It seems knowledge-intensive high-tech sectors are more likely to use formal identification systems although research suggests this is due more to the sophistication of, and nature of labor markets within sectors rather than the sector per se (Jones et al. 2012; Parry and Proctor-Thomson, 2013). However, scholars more typically describe current organizational practices (e.g. Derr, Jones and Toomey 1988; Miller and Desmarais 2007) or offer general frameworks and models devoted to the conceptualization and development of potential (e.g. Day 2001; Lewis and Heckman 2006; Silzer and Church 2009). Very few studies have collected data from the potential leader population itself (exceptions include Dries and Pepermans 2007; Marshall-Mines et al. 2000), or their managers. Lewis and Heckman's $(2006,142)$ review of practitioner-oriented publications suggest that, 'the topic has been enthusiastically pursued in the trade and popular press without being linked systematically to peer-reviewed, research-based findings'. There is clearly a need for researchers to identify reliable, valid and theoretically meaningful ways to increase the quality of leader identification and development in organizations.

This study draws on the existing literature (e.g. Day 2001; Dries and Pepermans 2012; Silzer and Church 2009) to empirically examine the extent to which employees' general mental ability (GMA), problem-solving skills, emotional intelligence (EI), work engagement and career aspiration contribute to the leadership potential ratings they receive. 
Empirically ascertaining the relative contribution of these factors in the prediction of leadership potential, from both the manager and employee perspective, will increase understanding of this important construct. There are also valuable practical implications in determining which aspects of employee capability managers (and employees) draw upon when making judgments about leadership potential and subsequent development. Greater familiarity with the complex expectations involved in recognizing leadership potential could assist and guide manager conversations with staff about their future career development. Employees increasingly involved in self-managing and shaping their own career and leadership opportunities will also benefit from these insights. De Vos and Soens (2008) showed how career insight explains the relationship between a protean career attitude (i.e. the extent to which an individual manages his or her career in a proactive and self-directed way) and career success. Thus, more clearly articulating to employees what is required of them (as well as the organization) to meet leadership expectations will enable more meaningful career choices (Parry and Proctor-Thomson, 2013).

Another aim of this study is to examine the level of agreement that exists between a manager and an employee regarding leadership potential ratings. Greater agreement might indicate better measure validity (Cook and Emler 1999). In practical terms greater agreement might lead to greater acceptance and uptake of developmental initiatives that follow on from leadership potential ratings (Heidemeier and Moser 2009). While acknowledging research showing manager and employee ratings of job performance and leadership development are vulnerable to halo effects and leniency (or strictness) biases (Heidemeier and Moser 2009), we contend there is overarching value in collecting information from both the manager and employee. For instance, it is important to have managers recognize, believe in and share the same leadership aspirations as their employees. It is also insufficient for managers to identify leadership potential unless employees themselves also aspire to leadership positions. Furthermore, any significant differences that are revealed point the way for future conversations between the manager and employee.

\section{Leadership potential}

Silzer and Church (2009, 378 (italics in the original)) state it is important to identify 'the talent that already exists in the organization and the employees who have the potential to be effective in other future roles, usually with much broader responsibilities, and at higher levels in the hierarchy'. Thus, the identification and management of leadership potential extends from the development of current performance for the next position, to long-term future development. It also includes an assessment of employee 'fit' with future roles that are usually broader in scope and have greater strategic consequences. This conceptualization corresponds with Day's (2001) view of leader development as capacity building across the organization.

A useful framework to consider the multifaceted nature of the leadership potential construct is Dries and Pepermans' (2012) two-dimensional model. The first dimension is labeled Conation versus cognition (i.e. heart versus head). While conation focuses on drive, 
motivation and action, cognition highlights the analytical skills held by the employee. The second dimension is labeled Extrapersonal versus intrapersonal (i.e. context versus self). The extrapersonal side represents the interaction of the individual with the external environment while the intrapersonal side focuses on the individual's inner life. In essence, this two-dimensional model consists of four quadrants (analytical skills, learning agility, drive and emergent leadership) all considered important qualities for leadership potential. These quadrants have parallels with other key researchers in the area as outlined below (e.g. DeRue et al. 2011; Silzer and Church 2009). The Dries and Pepermans' (2012) model guides our selection of predictors in this study to ensure that we utilize indicators to capture each of the dimensions of leadership potential within our organization.

Analytical skills includes the factors of intellectual curiosity, strategic insight, decision-making and problem-solving (high on cognition and extrapersonal focus). Learning agility involves a willingness to learn, EI and adaptability (high on cognition and intrapersonal focus). Both quadrants compare with DeRue et al.'s (2011) integrated model of leader effectiveness that shows leader traits and abilities (including intelligence and EI) predict future leader effectiveness. This also complements the foundational aspect of Silzer and Church's (2009) conceptualization of potential that incorporates foundational, growth and career dimensions. More specifically, Silzer and Church (2009) view Foundational characteristics as relatively stable across time and place, hard to change and including cognitive abilities, personality variables and interpersonal characteristics.

Drive encompasses an individual's results orientation, perseverance, dedication, commitment or engagement (high on conation and intrapersonal focus), while emergent leadership involves motivation to lead, self-promotion and stakeholder sensitivity (high on conation and extrapersonal focus) (Dries and Pepermans 2012). Drive shares similarities with Silzer and Church's (2009) growth dimension that encapsulates the notion of adaptability and energy while emergent leadership is consistent with Silzer and Church's (2009) career dimension that includes leadership skills and ambition. Acknowledging the multidimensional nature of leadership potential highlighted in this literature we consider the role of a range of different factors in determining ratings of leadership potential. Each of these factors, as we expect them to relate to ratings of employee leadership potential, is discussed below.

\section{GMA and problem-solving}

We propose that an employees' greater cognitive capacity (in this case, GMA and problem-solving skill) will predict higher ratings of their leadership potential. This aligns with Dries and Pepermans' (2012) analytical skills quadrant (comprising intellectual curiosity, strategic insight, problem-solving and decision-making) and Silzer and Church's (2009) foundational dimension described above. There is broad agreement that employee GMA is one of the best predictors of future leader performance (Hunter 1989; Schmidt and Hunter 2004). Adopting the most widely used measure of GMA, the Wonderlic Personnel Test (Wonderlic 1992) Hunter and his colleagues consistently demonstrate the 
positive relationship between GMA and job performance. The relationship is even stronger for jobs of increasing complexity that comprise leadership features (Schmidt and Hunter 2004).

Several researchers also propose that the capacity to transform information into action (i.e. via problem-solving) becomes more salient at higher levels in the organizational hierarchy as information, decisions and problems become more intricate (Dries and Pepermans 2012; Marshall-Mines et al. 2000; Mumford et al. 2000; Silzer and Church 2009). The ability to deal with increasing complexities and ambiguity is also a critical indicator of leadership potential. Leadership (as opposed to managerial or administrative roles) involves complex social problem-solving derived from intelligence and cognitive capabilities in which leaders identify key issues relevant to organizational goal attainment and generate solutions that address these issues. For the current study employees with greater GMA and problem-solving ability are expected to receive more favorable leadership potential ratings (by both self and manager).

\section{Emotional intelligence}

Emotional intelligence (EI) is the ability to be aware of and deal with one's own and others' emotions, especially in times of stress and ambiguity (Mayer and Salovey 1997; Troth et al. 2012; Wong and Law 2002). It is also one of the factors making up learning agility (Dries and Pepermans 2007, 2012). The importance of learning agility, or an employee's willingness and ability to learn from experience, is seen as critical to future leadership success by many researchers (e.g. Briscoe and Hall 1999; Dries and Pepermans 2007; Lombardo and Eichinger 2000). While junior staff cannot be expected to demonstrate advanced leadership competencies because of their career stage, they have had the opportunity to demonstrate the learning agility needed to acquire leadership competencies in the future. EI comprises skills that have been linked to adaptability and continuous learning (Briscoe and Hall 1999; Dries and Pepermans 2007) as well as intrapersonal skills (self-awareness and self-expression), interpersonal skills (conflict resolution) and stress management (emotional management and regulation) that contribute to life and career success. EI has also been conceptually and empirically linked to models of effective or transformational leadership (Barbuto and Burbach 2006) and leadership performance (Wong and Law 2002). Thus, it is expected employees high in EI will be rated more highly for leadership potential (by both self and manager).

\section{Engagement and career aspiration}

Employees with greater perceived workplace engagement and career aspiration are also expected to receive higher ratings of leadership potential. Employee work engagement is viewed as a motivational construct and a 'positive, fulfilling, work-related state of mind that is characterized by vigor, dedication, and absorption' (Schaufeli et al. 2002, 72). Several researchers demonstrate a positive relationship between work engagement and an individual's perceived leadership behavior (e.g. Avolio, Walumbwa and Weber 2009). Dries and Pepermans' (2012) drive quadrant of leadership potential also encapsulates 
engagement together with commitment, perseverance and dedication (high on conation and intrapersonal focus).

In terms of career aspiration, Tharenou (2001) and Tharenou and Terry (1998) demonstrate a greater desire to progress further or enter leadership roles (defined as career aspiration) predicts employee's actual advancement within the organizational hierarchy. Waldman, Galvin and Walumbwa (2013) show how motivation to lead is a key personal quality related to leadership potential in university students. Dries and Pepermans' (2012) emergent leadership dimension of potential (comprising motivation to lead, selfpromotion and stakeholder sensitivity) and Silzer and Church's (2009) career dimension (including leadership skills and ambition) also highlight the predictive role of career aspiration in employee ratings of leadership potential (by self and manager).

In sum, we predict the following:

Hypothesis 1a: Managers' perceptions of their employee's problem-solving ability, EI, engagement and career aspiration will have a positive relationship with their ratings of employee leadership potential.

Hypothesis 1b: Employees' GMA and perceptions of their own problem-solving, EI, engagement and career aspiration will have a positive relationship with their manager's ratings of leadership potential.

\section{Performance}

Leadership potential is more than current and previous job performance, despite performance often being utilized as a single determinant of potential identification (Miller and Desmarais 2007). Both Greer and Virick (2008) and Lombardo and Eichinger (2000) criticize the overreliance on performance evaluations to identify leadership potential, arguing that individuals typically require different skill sets and broader responsibilities in future leadership roles. An individual's knowledge and expertise as an engineer, for example, becomes less salient in leadership positions where greater strategic and people management skills are required. We concur with the significant conceptual differences between performance and leadership potential. However, we also recognize the role of job performance in determining an employee's initial consideration for future leadership development by the organization. As many organizations view performance as an important prerequisite for leadership potential identification, we also examine the role of employee performance in determining their leadership potential ratings. Thus,

Hypothesis 2a: Manager ratings of employee performance will have a positive relationship with their ratings of employee leadership potential.

Hypothesis 2b: Employee ratings of their own performance will have a positive relationship with their manager's ratings of their leadership potential.

\section{Multisource ratings of leadership potential}

Various stakeholders might be utilized to identify leadership potential including top management, human resource officers, line managers and the talented employee him/herself 
(Dries and Pepermans 2012; Silzer and Church 2009). We restrict our focus to employee self and manager ratings. Managerial views are critical as it is their identification and advocacy of an employee's potential that typically determines their subsequent allocation to leadership development opportunities in the APS. It is also preferable to reduce differences between employee and managerial perceptions of leadership potential to increase acceptance of potential ratings and ensure uptake of developmental pathways. Nevertheless, Hutchison and Burch (2011) show how strong multisource rater effects (i.e. discrepancy in ratings) for senior executive performance call into question the reliability and validity of critical tools used by human resources within organizations and ultimately impact on employee's acceptability of both the process and resulting interventions (e.g. career development options). Thus, assuming some degree of rater discrepancy is present we investigate the extent of agreement between manager and employee ratings of leadership potential and predict:

Hypothesis 3: Rater effects will be present for manager and employee ratings of the leadership potential predictors.

\section{Method}

\section{Organizational context}

This study occurred during 2010 in a large Australian government department with a geographically disbursed workforce of over 20000 employees. The specialist technical skills of this workforce include finance, law, accounting and economics. A large proportion of the workforce also fulfils important non-technical roles such as program administration, management and corporate support, requiring significant experience and contextual understanding for effective delivery. Workforce planning research had indicated some significant succession management risks due to the aging profile of key technical and nontechnical employees, coupled with a lack of readily available replacements in the external employment market. Approximately $45 \%$ of the workforce in this department is aged 45 years or over and less than $15 \%$ are under 29 years with many key leadership roles biased heavily towards older workers. In response to the potential shortfall of critical skill sets, the organization's corporate plan includes an outcome to 'build bench strength in critical capabilities for the future: deliver effective succession and career management and transition strategies'. This data collection formed one way of ascertaining the capabilities of employees thought to be indicative of leadership potential.

\section{Sample and procedure}

Two separate surveys were administered approximately 3-4 weeks apart to 178 employees at time 1 and 167 employees at time 2, resulting in 166 employees completing both data collection phases. A survey was also administered to their 149 managers. One hundred and twenty-eight managers rated one employee, 15 managers rated two employees and three managers rated three employees. 
Asia Pacific Journal of Human Resources ••

A two-phase approach to data collection was adopted to reduce the occurrence of common method variance (Podsakoff, MacKenzie and Podsakoff 2012) and to flexibly accommodate the time taken from employees' core job requirements. At time 1 and time 2 respectively, $77(43.3 \%)$ and $75(44.9 \%)$ employees were male. A range of job levels were represented from APS2 (APS levels range from 1 to 6) to Executive Level 2.1. The modal level was APS6 (38.8\%). Age ranged from less than 25 years to 64 years. Modal age categories were the 35-44 year olds (32\%) and 45-54 year olds (32.6\%). Fifty-eight $(33.7 \%)$ had worked in their current role for less than 1 year, $103(59.9 \%)$ had been in their role for 1 to 5 years, and the remaining sample for over 5 years. Utilizing the existing industry contact of one of the researchers we were provided with access to employees across the organization. Employees self-nominated to be a part of this study following several internal communications within the organization. Once employees self-nominated, their managers were approached to rate each of their participating staff.

\section{Measures}

Time 1: Manager survey and employee survey (Part 1)

Managers were asked to rate their employee on problem-solving ability, EI, engagement, career aspiration, job performance and leadership potential. Employees also assessed themselves on these variables (except for performance and leadership potential) in a similar survey administered separately.

Problem-solving. This 7-item problem-solving measure, based on Mumford et al.'s (2000) leader problem-solving skills scale, used a 5-point rating scale from 1 (='requires development') to 5 (='demonstrates ability amongst the best I've seen'). An example item includes, 'He/she understands various elements that need to be integrated to solve bigger organizational problems'.

Emotional intelligence. The EI measure comprised two statements from Wong and Law's (2002) Emotional Intelligence Scale (WLEIS) and used a 5-point scale from 1 (='requires development') to 5 (='demonstrates ability amongst the best I've seen'). An example item includes, 'He/she shows a good understanding of the feelings and emotions of others'.

Engagement. The engagement measure comprised nine statements taken from Saks (2006) and Allen and Meyer (1990) and used a 5-point scale from 1 (='never') to 5 (='always'). An example item includes, 'He/she is enthusiastic and enjoys their current role'.

Career aspiration. The measure for career aspiration comprised five items from Tharenou (2001) and Tharenou and Terry's (1998) Desired Managerial Aspiration scale and used a 5-point scale from 1 (='never') to 5 (='always'). An example item includes, 'He/she displays ambition for promotion/progression to more senior roles'. 
Job performance. Managers rated employee's performance by circling one of the following five descriptions that best captures their job performance: 1 (='requires development'), 2 (='entry level/new role'), 3 (='fully effective'), 4 (='superior') and 5 (='exceptional').

Leadership potential. Managers rated employee's leadership potential by circling one of the following five descriptions regarding specific future development: 1 (='encourage to improve performance'); 2 (='continue with current development'); 3 (='develop with a view to the next level'); 4 (='develop for next level of leadership') and 5 (='actively develop for next level of leadership now - high end development').

\section{Time 2: Employee survey (Part 2)}

The second employee survey comprised measures of GMA and performance. Demographic data were also collected.

General mental ability. The Wonderlic Personnel Test (WPT) was used to assess GMA. The WPT is an ability test assessing vocabulary, arithmetic reasoning, and spatial relations. It contains 50 items and takes 12 minutes to administer. An example item includes asking a participant to observe a set of words, and then to select one that is irrelevant to the others. Other items require participants to solve word problems utilizing various algebraic and geometric techniques. The WPT is psychometrically equivalent to other well-known measures of cognitive ability (Schmidt and Hunter 2004).

Performance. A 6-item measure of employee's job performance was utilized drawing on performance measures from Ang, Van Dyne and Begley (2003) and Chen, Tsui and Farh (2002). A 7-point scale was employed from 1 (='strongly disagree') to 7 (='strongly agree'). An example item includes, 'I produce high quality work'.

Prior to hypotheses testing, confirmatory factor analysis (CFA) using AMOS version 19 structural equation modeling software (Arbuckle 2010) established the construct validity of the main variables of problem-solving, engagement and career aspiration (manager and employee ratings) and employee self-ratings of performance (time 2 survey). All model estimations on covariance matrices used the maximum likelihood procedure with Bollen-Stine bootstrapping post-hoc adjustments to account for any non-normality (Bollen and Stine 1992). To assess the overall fit of each model, we followed Crawshaw, van Dick and Brodbeck's (2012) protocol and examined the models on Bentler's (1990) comparative fit index (CFI) and Steiger's (2000) root mean square error of approximation (RMSEA). All models achieved acceptable fit with CFI values larger than 0.90 and RMSEA values less than 0.05 . However, some modification and respecification was required for problem-solving and engagement.

\section{Results}

Table 1 presents the descriptive statistics for all variables and correlations between the measures used in the study. The Cronbach alphas show good levels of reliability, ranging 
JOBNAME: No Job Name PAGE: 10 SESS: 11 OUTPUT: Tue Feb 25 09:11:37 2014 SUM: EABFB1AD

/Xpp84/wiley_journal/APHR/aphr_v0_i0/aphr_12034

Asia Pacific Journal of Human Resources

Table 1 Descriptive statistics and correlations

\begin{tabular}{|c|c|c|c|c|c|c|c|c|c|c|c|c|c|}
\hline & 1 & 2 & 3 & 4 & 5 & 6 & 7 & 8 & 9 & 10 & 11 & Mean & SD \\
\hline \multicolumn{14}{|l|}{ Ability } \\
\hline 1 GMA (E) & - & & & & & & & & & & & 29.17 & 4.94 \\
\hline 2 Problem-solving (E) & .07 & $(.75)$ & & & & & & & & & & 3.50 & .63 \\
\hline 3 Problem-solving (M) & .07 & $.19^{* *}$ & $(.81)$ & & & & & & & & & 3.45 & .71 \\
\hline \multicolumn{14}{|l|}{ Learning agility } \\
\hline $4 \mathrm{EI}(\mathrm{E})$ & -.04 & $.36^{* *}$ & .07 & $(.86)$ & & & & & & & & 5.88 & .59 \\
\hline 5 EI (M) & -.05 & -.02 & $.59^{* *}$ & .09 & $(.84)$ & & & & & & & 3.60 & .83 \\
\hline \multicolumn{14}{|l|}{ Drive } \\
\hline 6 Engagement (E) & -.0 & $.25^{\star *}$ & .12 & $.43^{* *}$ & .09 & $(.85)$ & & & & & & 4.22 & .47 \\
\hline 7 Engagement (M) & $-.17^{\star}$ & .03 & $.37^{* *}$ & .07 & $.34^{* *}$ & $.23^{* \star}$ & $(.89)$ & & & & & 4.18 & .54 \\
\hline \multicolumn{14}{|l|}{ Emergent leadership } \\
\hline 8 Career aspire (E) & .00 & $.30^{\star *}$ & -.03 & $.26^{\star *}$ & -.14 & $.27^{* *}$ & -.02 & $(.90)$ & & & & 4.17 & .53 \\
\hline 9 Career aspire (M) & -.02 & $.16^{\star *}$ & $.45^{\star \star}$ & .02 & $.22^{\star *}$ & $.23^{* *}$ & $.59^{* \star}$ & $.24^{\star \star}$ & $(.80)$ & & & 3.87 & .54 \\
\hline \multicolumn{14}{|l|}{ Performance } \\
\hline 10 Perform (E) & .06 & $.39^{* \star}$ & $.29^{\star *}$ & $.39^{* *}$ & .11 & $.56^{\star *}$ & $.23^{* *}$ & $.32^{\star *}$ & $.27^{\star *}$ & $(.83)$ & & 6.12 & .62 \\
\hline 11 Perform (M) & -.10 & .08 & $.65^{* *}$ & -.08 & $.48^{* *}$ & .15 & $.42^{* *}$ & -.08 & $.48^{\star *}$ & $.26^{* *}$ & & 3.48 & .63 \\
\hline 12 Leadership potential & $.20^{\star *}$ & .12 & $.55^{\star \star}$ & .01 & $.43^{* *}$ & .10 & $.43^{* *}$ & .09 & $.59^{* *}$ & $.16^{*}$ & $.53^{* *}$ & 3.64 & .77 \\
\hline
\end{tabular}

${ }^{*} p<0.05,{ }^{* *} p<0.01 . n=111$; Cronbach alphas for scales are reported in italic on the diagonal of the correlation matrix. GMA $=$ General mental ability; $\mathrm{M}=$ Manager, $\mathrm{E}=$ Employee.

Table 2 Regression analysis for leadership potential with manager ratings of predictor variables

\begin{tabular}{ll}
\hline Variable & $\beta$ \\
\hline Problem-solving & $.19^{*}(.09)$ \\
Emotional intelligence & $.01(.07)$ \\
Engagement & $.17^{\star}(.11)$ \\
Aspiration & $.38^{* * *}(.11)$ \\
Job performance & $.17^{+}(.09)$ \\
& $\mathrm{F}(5,115)=27.99^{* * *}$ \\
& $R^{2}=.55$ \\
\hline
\end{tabular}

${ }^{+} p=0.06 ;{ }^{\star} \mathrm{p}<0.05,{ }^{\star *} \mathrm{p}<0.01,{ }^{\star * \star} \mathrm{p}<0.001$.

$n=120$.

from 0.80 to 0.92 for all variables. The correlations between manager ratings of problemsolving, EI, engagement, career aspiration and employee performance were all significantly and positively related to their ratings of an employee's leadership potential (hypotheses 1a and 2a). While an employee's GMA was positively related to ratings of their leadership potential (hypothesis $1 \mathrm{~b}$ ), self-ratings of problem-solving ability, EI, engagement, career aspiration and job performance were not (hypothesis $1 \mathrm{~b}$ and $2 \mathrm{~b}$ ).

Given the inter-correlations among the major variables, we conducted two separate regressions predicting manager ratings of leadership potential. The first regression used manager ratings (Table 2) of problem-solving ability, EI, engagement, aspiration and performance while the second regression (Table 3) used employees' GMA scores and self-ratings of problem-solving, EI, engagement, aspiration and performance. 
JOBNAME: No Job Name PAGE: 11 SESS: 11 OUTPUT: Tue Feb 25 09:11:37 2014 SUM: 3DA1E477

/Xpp84/wiley_journal/APHR/aphr_v0_i0/aphr_12034

Ashlea C Troth and Christopher Gyetvey

Table 3 Regression analysis for leadership potential with employee ratings on predictor variables

\begin{tabular}{lc}
\hline Variable & $\beta$ \\
\hline General mental ability & $.00(.05)$ \\
Problem-solving & $.14(.11)$ \\
Emotional intelligence & $.00(.10)$ \\
Engagement & $-.16(.13)$ \\
Aspiration & $.25^{*}(.11)$ \\
Job performance & $.10(.09)$ \\
& $\mathrm{F}(6,131)=2.46^{*}$ \\
& $R^{2}=.10$ \\
& Adjusted $R^{2}=.06$ \\
\hline
\end{tabular}

${ }^{*} p<0.05 ; n=120$.

Table 2 shows manager ratings of an employee's problem-solving ability, EI, work engagement, career aspiration and performance combine to significantly predict their ratings of that individual's leadership potential, $\mathrm{F}(5,115)=27.99, p<0.001$ and Adjusted $R^{2}=0.53$. Significant positive $\beta$ weights were found for problem-solving $(\beta=0.19, p<$ $0.05)$, engagement $(\beta=0.17, p<0.05)$, career aspiration $(\beta=0.38, p<0.0001)$ and job performance $(\beta=0.17, p=0.06$ ) (hypotheses 1a and 2a). Table 3 shows employee's GMA and their self-ratings of problem-solving ability, EI, work engagement, career aspiration and performance also combined to significantly predict their manager's ratings of their leadership potential, $\mathrm{F}(6,131)=2.46, p<0.05$ and Adjusted $R^{2}=0.06$. However, a significant positive $\beta$ weight was found for career aspiration only $(\beta=0.25, p<0.05)$.

A series of intra-class correlation (ICCs) coefficients were also calculated to assess the extent of agreement among employees and their managers for ratings of problem-solving ability, EI, work engagement and career aspiration (hypothesis 3). Based on recommendations by Shrout and Fleiss (1979) and the work of Hutchison and Burch (2011), a one-way random effects model was used to assess the reliability of any single rater's rating and the reliability of the average ratings for a given measure and given employee. These are referred to as ICC $(1,1)$ and ICC $(1, \mathrm{k})$, respectively. The ICC $(1,1)$ s were 0.24 for problemsolving, 0.19 for EI, 0.26 for engagement and 0.39 for aspiration. The ICC $(1, \mathrm{k}) \mathrm{s}$ were 0.38 for problem-solving, 0.32 for EI, 0.42 for engagement and 0.56 for aspiration. Overall, there is low reliability between managers and employees for these indicators of leadership potential, and the ICCs fall below the traditional threshold of 0.70 and LeBreton and Senter's (2008) stricter threshold of 0.90. It appears rater effects are present.

\section{Discussion}

Our predictions were partly supported. At the bivariate level (Table 1) it seems managers consider employee GMA, their level of problem-solving capability, EI, engagement, career aspiration (hypothesis 1a) and job performance (hypothesis 2a) when making judgments 
about their leadership potential, although the effect of GMA and EI did not hold in further multivariate analyses. This contributes to the small body of empirical research using manager ratings (e.g. Dries and Pepermans 2007; Marshall-Mines et al. 2000) and supports other empirical and conceptual work suggesting links between future leadership capability and problem-solving skills (DeRue et al. 2011; Dries and Pepermans 2012), work engagement (Avolio, Walumbwa and Weber 2009) and career aspiration (Tharenou 2001).

However, EI did not contribute to leadership potential ratings when all the predictors were considered simultaneously and this was unexpected given its links to leadership effectiveness in the literature (e.g. Briscoe and Hall 1999; Dries and Pepermans 2007, 2012). One explanation is that specific EI abilities might have a stronger effect on leadership potential ratings than the overall level of employee EI captured by our measure. It is conceivable that the ability to 'manage own' and 'manage others' emotions' might be more strongly predictive of leadership potential than 'awareness of own' and 'awareness of others' emotions'. Other researchers demonstrate the value in examining EI at the separate ability level (e.g. Troth et al. 2012).

Similar to EI, GMA correlated significantly only with leadership potential at the bivariate level. This was surprising given considerable empirical support in the literature linking GMA to samples of job performance and subsequent supervisor ratings of performance (Schmidt and Hunter 2004). It is possible that managers in our sample do not consider GMA in their ratings once a threshold level of employee GMA is achieved. Perhaps intelligence only allows employees to progress so far in leadership terms without the possession of other skills (i.e. interpersonal and motivational). The mean level of GMA in our sample is also high (with small standard deviation) compared with Wonderlic norms restricting the range for analysis. In contrast, problem-solving independently adds to the prediction of leadership potential ratings (as distinct from performance ratings) (Rees, Earles and Teachout 1994). According to Schmidt and Hunter (2004) many problemsolving measures assess employee aptitude (or capture cognitive abilities narrower than GMA) that are job or organization specific and sometimes more relevant.

Despite researchers conceptually distinguishing between leadership potential and employee performance (Greer and Virick 2008), our sample of managers appears to rely to some extent on performance to inform their leadership potential decisions (hypothesis 2a). Importantly, the managers also utilize other information such as employee level of problem-solving, engagement and aspiration to make decisions. This supports Silzer and Church's (2009) argument that potential comprises foundational and growth dimensions as well as the commonly utilized career dimension indices of performance, technical and functional skills. In essence, DeRue et al.'s (2011) and Marshall-Mines et al.'s (2000) findings that leadership effectiveness contains important intrapersonal factors is supported by our data, at least in terms of perceptions of future leadership effectiveness. There is also support for Dries and Pepermans' (2012) multidimensional conceptualization of leadership potential. It seems that for an employee to be viewed as having leadership potential, he or she needs to demonstrate elements of analytical ability, drive and emergent leadership, in addition to performance ratings. 
While employee self-rated career aspiration was linked to their manager's ratings of leadership potential, perceptions of their own problem-solving ability, EI, work engagement and job performance were unrelated to the leadership potential rating given by their manager within the regression analysis (hypotheses $1 \mathrm{~b}$ and $2 \mathrm{~b}$ ). Although Table 1 shows positive and significant correlations between self and manger ratings on problemsolving, engagement, aspiration and performance measures (ranging from $\mathrm{r}=0.19, p<$ 0.05 to $r=0.26 p<0.01$ ), significant rater source effects were present (hypothesis 3 ). Rater effects are a salient though not unexpected finding. Small effect sizes are often found for multisource ratings (Hutchison and Burch 2011), especially regarding perceptions of competencies (Brownell 2006), with correlations averaging $\mathrm{r}=0.14, p<0.05$ between self-assessed and peer-assessed measures (Ready et al. 2000). This is why human resource researchers often advocate the use of multisource information for primarily developmental purposes (Shields 2007) with variations used to trigger important conversations about differences in understanding, in this case about what constitutes leadership potential.

\section{Implications for human resource managers}

Our findings show that managers consider employee problem-solving, engagement, career aspiration and performance when making judgments about their leadership potential. This suggests it would be worthwhile openly communicating to staff via formal and informal conversations those skills, abilities, attitudes and behaviors managers consider important for future leadership development (Hollenbeck, McCall and Silzer 2006). In addition to performing well in the job, employees need to convey their level of engagement and aspiration to management to be considered for leadership roles. This has important human resource implications for those employees not working within direct line of sight to their manager. It also has implications for employees from minority backgrounds who may find it challenging to communicate their career aspirations upwards. The importance of educating managers about these barriers, and the perceptual bias they may utilize when determining an employee's future potential, is underscored here.

The original impetus for identifying the components that predict ratings of leadership potential within this organization was the aging workforce and leadership roles that had necessitated calls for better succession planning. This approach aligns with Cappelli's (2008) and Parry and Proctor-Thomson's (2013) notion of succession management that advocates the establishment of talent pools and the development of employees with broad and general competencies that fit a range of jobs, as opposed to specialized jobs. One specific initiative has been to leverage the knowledge and experience of leaders approaching the end of their career by pairing them with early career employees identified with leadership potential to nurture and develop their competencies further. Developing multiple networks, peer learning relationships and the ability to learn and develop on the job are also seen as particularly useful strategies by the organization.

The results showing low concurrence between employee and manager ratings emphasizes the important function of honest and frank conversations between managers and 
their staff when discussing leadership potential and career goals. Otherwise there is a significant risk that disagreement regarding leadership potential, on identification tools or in terms of career development conversations, will impact on an employee's acceptability of both the process and the resulting career development options provided. Hutchison and Burch (2011) advocate the need for such data to be treated cautiously in terms of 'aggregating' manager and employee ratings to give an overall 'score' for employee performance (or leadership potential) to make subsequent decisions.

From a developmental perspective, however, using this information about perceptual similarities and differences is invaluable in helping trigger constructive discussion and to 'shift' employee perceptions and behaviors to align better with organizational expectations (Shields 2007). Different raters also provide unique and meaningful information that is particularly relevant if measuring relationship-building or leadership behaviors that are more evident to subordinates than to superiors (Yammarino 2003). Thus, disparate ratings offer an opportunity for constructive discussion and clarification about varying perceptions of leadership potential and enable the management of realistic expectations of both employees and managers. This could occur as a formal moderation session to increase alignment of the separate ratings or be achieved via greater two-way dialogue in annual performance discussions. In essence, if an organization's goal is to promote a common understanding of what constitutes leadership potential, then different ratings provide a useful starting point to begin the process. Subsequent conversations and workshops designed to educate employees about the key elements of leadership that upper management looks for should comprise the initial starting point to ensure greater convergence in viewpoints.

\section{Limitations and future research}

The contributions of our research should be viewed in light of a number of potential methodological limitations that are presented here as possible opportunities for future research and methodological development. First, we acknowledge the predominantly selfreport nature of the employee version of the assessment tool (except GMA). Employee social desirability is likely to inflate levels of performance, problem-solving ability, EI, engagement and aspiration. Common method variance is also a problem for manager ratings. Although the ideal was to collect ratings of leadership potential at a different time to ability, engagement and aspiration ratings, our challenge was to collect data from managers in a real organization who had competing time demands.

We also acknowledge our study focused on the assessment of leadership potential identification as the criterion variable. It is important for future research to follow up this identification process with an assessment of the leadership and career challenge opportunities given, and their success. Longitudinal work would be beneficial to identify whether identification itself predicted future leadership success in the future. In practical terms, feedback of this type of information to the manager and employee would ensure future traction of the leader potential identification process. 
We acknowledge our study was limited to an examination of the intrapersonal components of leadership potential. In future work, we believe it is important to consider Day's (2001) view that leadership and leadership development is a complex interaction between the designated (or potential) leaders and the social and organizational environment. Considering the role of social capital skills (e.g. networking and political skills) in leadership potential perceptions would be an interesting future direction. In a series of letters discussing the advantages and disadvantages of leadership competency models, Hollenbeck, McCall and Silzer (2006) discuss how both person and situation variables are important, as well the interaction between these two sets of variables, in leadership effectiveness. To be effective, leaders not only need to have some learning abilities, they also need to be put in situations where they learn new things.

We recognize this study is restricted to one organization within the APS and this limits the generalizability of our findings to other public sector and private industry contexts. However, we do expect our findings to have relevance to other organizations similarly experiencing an aging workforce with key leadership positions skewed towards older workers which is a common scenario in the Australian public sector. One future research direction is to examine whether a different pattern of predictors emerge as salient for leadership potential identification in highly competitive workplaces with a different workforce profile.

Finally, while we have considered leadership potential from the employee perspective, we do acknowledge Collings and Mellahi's (2009) argument that it is equally important to identify key positions that have the potential to differentially impact on the competitive advantage of the organization. The identification of key positions, rather than talented individuals per se, is fundamental. Thus, as well as identifying a pool of employees with leadership potential, a good leadership potential strategy should involve the systematic identification of key positions that contribute to the organization's strategic outcomes.

Ashlea C Troth (PhD, Queensland) is an associate professor in the Griffith Business School, Brisbane, Australia.

Christopher Gyetvey (BS (Hons), Queensland) is a director within the Australian Taxation Office.

\section{References}

Advisory Group for the Reform of Australian Government Administration (2010) Ahead of the game: Blueprint for the reform of Australian government administration. Australian Government Department of the Prime Minister and Cabinet, Canberra.

Allen NJ and JD Meyer (1990) The measurement and antecedents of affective, continuance and normative commitment to the organization. Journal of Occupational Psychology 63, 1-18.

Ang S, L Van Dyne and TM Begley (2003) The employment relationships of foreign workers versus local employees: A field study of organizational justice, job satisfaction, performance, and OCB. Journal of Organizational Behavior 24, 561-583.

APSC (2010) State of the service report 2009-10. APSC, Canberra. 
JOBNAME: No Job Name PAGE: 16 SESS: 11 OUTPUT: Tue Feb 25 09:11:37 2014 SUM: C69E54ED

/Xpp84/wiley_journal/APHR/aphr_v0_i0/aphr_12034

Asia Pacific Journal of Human Resources $\bullet$

Arbuckle JL (2010) AMOS 19.0 user's guide. SPSS, Chicago, IL.

Avolio BJ, FO Walumbwa and TJ Weber (2009) 'Leadership: Current theories, research, and future directions. Annual Review of Psychology 60, 421-449.

Barbuto JE and ME Burbach (2006) The emotional intelligence of transformational leaders: A field study of elected officials. Journal of Social Psychology 146(1), 51-64.

Barney JB and PM Wright (1998) On becoming a strategic partner: The role of human resources in gaining competitive advantage. Human Resource Management 37(1), 31-46.

Bentler PM (1990) Comparative fit indexes in structural models. Psychological Bulletin 107, 238-246.

Bhatnagar J (2007) Talent management strategy of employee engagement in Indian ETES employees: Key to retention. Employee Relations 29(6), 640-663.

Bollen KA and RA Stine (1992) Bootstrapping goodness-of-fit measures in structural equation models. Sociological Methods and Research 21, 205-229.

Briscoe JP and DT Hall (1999) Grooming and picking leaders using competency frameworks: Do they work? An alternative approach and new guidelines for practice. Organizational Dynamics 28(2), 37-52.

Brownell J (2006) Meeting the competency needs of global leaders: A partnership approach. Human Resource Management 45(3), 309-336.

Cappelli P (2008) Talent on demand. Harvard Business School Press, Boston, MA.

Chen ZX, AS Tsui and JL Farh (2002) Loyalty to supervisor vs. organizational commitment: Relationships to employee performance in China. Journal of Occupational and Organizational Psychology $75,339-356$.

Collings DG and K Mellahi (2009) Strategic talent management: A review and research agenda. Human Resource Management Review 19, 304-313.

Cook T and N Emler (1999) Bottom-up versus top-down evaluations of candidates' managerial potential: An experimental study. Journal of Occupational and Organizational Psychology 72, 423439.

Crawshaw JR, R van Dick and FC Brodbeck (2012) Opportunity, fair process and relationship value: Career development as a driver of proactive work behaviour. Human Resource Management Journal 22(1), 4-20.

Day DV (2001) Leadership development: A review in context. Leadership Quarterly 11(4), 581-613.

De Vos A and N Soens (2008) Protean attitude and career success: The mediating role of selfmanagement. Journal of Vocational Behavior 73, 449-456.

Derr CB, C Jones and EL Toomey (1988) Managing high-potential employees: Current practices in thirty-three US corporations. Human Resource Management 27(3), 273-290.

DeRue DS, JD Nahrang, N Wellman and SE Humphrey (2011) Trait and behavioural theories of leadership: An integrated meta-analytic test of their relative validity. Personnel Psychology 64, $7-52$.

Dries N and R Pepermans (2007) Using emotional intelligence to identify high potential: A metacompetency perspective. Leadership and Organizational Development Journal 28, 8, 749-770.

Dries N and R Pepermans (2008) Real high-potential careers: An empirical study into the perspectives of organizations and high potentials. Personnel Review 37(1), 85-108.

Dries N and R Pepermans (2012) How to identify leadership potential: Development and testing of a consensus model. Human Resource Management 51, 361-385.

Freyens BP (2010) Managing skill shortages in the Australian public sector: Issues and perspectives. Asia Pacific Journal of Human Resources 48(3), 262-286. 
JOBNAME: No Job Name PAGE: 17 SESS: 11 OUTPUT: Tue Feb 25 09:11:37 2014 SUM: C3157239

/Xpp84/wiley_journal/APHR/aphr_v0_i0/aphr_12034

Ashlea C Troth and Christopher Gyetvey

Greer CR and M Virick (2008) Diverse succession planning: Lessons from the Industry leaders. Human Resource Management 47(2), 351-367.

Heidemeier H and K Moser (2009) Self-other agreement in job performance ratings: A metaanalytic test of a process model. Journal of Applied Psychology 94(2), 353-370.

Hirschfield RR and CH Thomas (2011) Age- and gender-based role incongruence: Implications for knowledge mastery and observed leadership potential among personnel in a leadership development program. Personnel Psychology 64, 661-692.

Holland P, C Sheehan and H De Cieri (2007) Attracting and retaining talent: Exploring human resources development trends in Australia. Human Resource Development International 10(3), 247-262.

Hollenbeck GP, MW McCall and RF Silzer (2006) Leadership competency models. Leadership Quarterly $17,398-413$.

Hunter JE (1989) The Wonderlic Personnel Test as a predictor of training success and job performance. Wonderlic Personnel Test, Inc, Libertyville, IL.

Hutchings K and P Holland (2007) Recent advances in HRD in Australia: Application and implications for international HRD. Human Resource Development International 10(3), 243246.

Hutchison A and GJ Burch (2011) Senior-executive performance: Interrater reliability and rater effects in multisource ratings. Asia Pacific Journal of Human Resources 49(4), 425-439.

Jones JT, M Whitaker, PS Seet and J Parkin (2012) Talent management in practice in Australia: Individualistic or strategic? An exploratory study. Asia Pacific Journal of Human Resources 50(4), 399-420.

LeBreton JM and JL Senter (2008) Answers to 20 questions about interrater reliability and interrater agreement. Organizational Research Methods 11(4), 815-852.

Lewis RE and RJ Heckman (2006) Talent management: A critical review. Human Resource Management Review 16, 139-154.

Lombardo MM and RW Eichinger (2000) High potentials as high learners. Human Resource Management 39(4), 321-329.

Marshall-Mines JC, EA Fleishman, JA Martin, SJ Zaccaro, WA Baughman and ML McGee (2000) Development and evaluation of cognitive and metacognitive measures for predicting leadership potential. Leadership Quarterly 11(1), 135-153.

Mayer JD and P Salovey (1997) What is emotional intelligence? Implications for educators. In P Salovey and D Sluyter (eds) Emotional development, emotional literacy and emotional intelligence, 3-31. Basic Books, New York.

Miller D and S Desmarais (2007) Developing your talent to the next level: Five best practices for leadership development. Organization Development Journal 25(3), 37-43.

Mumford DM, SJ Zaccaro, FD Harding, TO Jacobs and EA Fleishman (2000) Leadership skills for a changing world: Solving complex social problems. Leadership Quarterly 11(1), 11-35.

Parry KW and SB Proctor-Thomson (2003) Leader career development: Who should take responsibility?, Asia Pacific Journal of Human Resources 41(3), 316-337.

Podsakoff PM, SB MacKenzie and NP Podsakoff (2012) Sources of methods bias in social science research and recommendations on how to control it. Annual Review of Psychology 63, 539-569.

Ready RE, LA Clark, D Watson and K Westerhouse (2000) Self- and peer-reported personality: Agreement, trait ratability, and the self-based heuristic. Journal of Research in Personality 34, $208-244$. 
JOBNAME: No Job Name PAGE: 18 SESS: 11 OUTPUT: Tue Feb 25 09:11:37 2014 SUM: 96B1C093

/Xpp84/wiley_journal/APHR/aphr_v0_i0/aphr_12034

Asia Pacific Journal of Human Resources

Rees MJ, JA Earles and MS Teachout (1994) Predicting job performance: Not much more than g. Journal of Applied Psychology 79(4), 518-524.

Saks AM (2006) Antecedents and consequences of employee engagement. Journal of Managerial Psychology 21(7), 600-619.

Schaufeli W, M Salanova, V González-Romá and AB Bakker (2002) The measurement of engagement and burnout: A two sample confirmatory factor analytic approach. Journal of Happiness Studies 3, 71-92.

Schmidt FL and J Hunter (2004) General mental ability in the world of work: Occupational attainment and job performance. Journal of Personality and Social Psychology 86(1), 162-173.

Shields J (2007) Managing employee performance and reward: Concepts, practices, strategies. Cambridge University Press, Cambridge.

Shrout PE and JL Fleiss (1979) Intraclass correlations: Uses in assessing rater reliability. Psychological Bulletin 86(2), 420-428.

Silzer R and AH Church (2009) The pearls and perils of identifying potential. Industrial and Organizational Psychology 2, 377-412.

Steiger JH (2000) Point estimation, hypothesis testing, and interval estimation using RMSEA: Some comments and a reply to Hayduk A. Glaser. Structural Equation Modeling 7(2), 149-162.

Tharenou P (2001) Going up? Do traits and informal social processes predict advancing in management?, Academy of Management Journal 44(3), 1005-1017.

Tharenou P and DJ Terry (1998) Reliability and validity of scores on scales to measure managerial aspirations. Educational and Psychological Measurement. 58, 475-492.

Troth AC, PJ Jordan, SA Lawrence and H Tse (2012) A multilevel model of emotional skills, communication performance, and task performance in teams. Journal of Organizational Behavior 33, $700-722$.

Vloeberghs D, R Pepermans and K Thielemans (2005) High-potential development policies: An empirical study among Belgian companies. Journal of Management Development 24(6), 546-558.

Waldman DA, BM Galvin and FO Walumbwa (2013) The development of motivation to lead and leader role identity. Journal of Leadership \& Organizational Studies 20(2), 156-168.

Wonderlic E (1992) Wonderlic personnel test. WPTI, Libertyville, IL.

Wong CS and KS Law (2002) The effects of leader and follower emotional intelligence on performance and attitude: An exploratory study. Leadership Quarterly 13, 243-274.

Yammarino FJ (2003) Modern data analytic techniques for multisource feedback. Organizational Research Methods 6(1), 6-14. 